\title{
Localization of the $\mathbf{2 6 S}$ proteasome during mitosis and meiosis in fission yeast
}

\section{Caroline R.M.Wilkinson, Mairi Wallace, Mary Morphew ${ }^{1}$, Paul Perry, Robin Allshire, Jean-Paul Javerzat ${ }^{2}$, J.Richard McIntosh ${ }^{1}$ and Colin Gordon ${ }^{3}$}

\author{
MRC Human Genetics Unit, Western General Hospital, Crewe Road, \\ Edinburgh, EH4 2XU, UK, ${ }^{1}$ Department of Molecular, Cellular and \\ Developmental Biology, University of Colorado, Boulder, \\ CO 80309-0347, USA and ${ }^{2}$ Institut de Biochimie et Genetique \\ Cellulaires, 1 rue Camille Saint Saens, 33077 Bordeaux, Cedex, \\ France \\ ${ }^{3}$ Corresponding author \\ e-mail: colin@hgu.mrc.ac.uk
}

The 26S proteasome is a large multisubunit complex involved in degrading both cytoplasmic and nuclear proteins. We have investigated the localization of this complex in the fission yeast, Schizosaccharomyces pombe. Immunofluorescence microscopy shows a striking localization pattern whereby the proteasome is found predominantly at the nuclear periphery, both in interphase and throughout mitosis. Electron microscopic analysis revealed a concentration of label near the inner side of the nuclear envelope. The localization of green fluorescent protein (GFP)-tagged 26S proteasomes was analyzed in live cells during mitosis and meiosis. Throughout mitosis the proteasome remained predominantly at the nuclear periphery. During meiosis the proteasome was found to undergo dramatic changes in its localization. Throughout the first meiotic division, the signal is more dispersed over the nucleus. During meiosis II, there was a dramatic re-localization, and the signal became restricted to the area between the separating DNA until the end of meiosis when the signal dispersed before returning to the nuclear periphery during spore formation. These findings strongly imply that the nuclear periphery is a major site of protein degradation in fission yeast both in interphase and throughout mitosis. Furthermore they raise interesting questions as to the spatial organization of protein degradation during meiosis.

Keywords: cytology/meiosis/mitosis/proteasome/yeast

\section{Introduction}

Ubiquitin-mediated degradation is the main non-lysosomal proteolytic pathway in eukaryotic cells. A number of important regulatory proteins are degraded in this way including cyclins, cyclin-dependent kinase (CDK) inhibitors, p53, NF- $\mathrm{kB}$, c-Fos, c-Jun, c-myc and membrane proteins such as CFTR. Other substrates for this pathway include denatured or abnormally folded proteins (reviewed in Ciechanover, 1994; Hochstrasser, 1995; Jentsch and Schlenker, 1995; Coux et al., 1996). Recent studies have also elucidated the role of the cytosolic-ubiquitin pathway in the degradation of luminal components of the endoplasmic reticulum (ER). Proteins are exposed to the cytosol for degradation in a process mediated by a functional translocon (Biederer et al., 1996; Hiller et al., 1996; Werner et al., 1996).

Proteins destined for degradation are targeted by the addition of a poly-ubiquitin chain. Ubiquitin is a 76 amino acid protein which is highly conserved amongst eukaryotes (Hershko, 1988). Through the actions of an activating enzyme (E1), a ubiquitin-conjugating enzyme (E2) and possibly a ubiquitin ligase factor, (E3), a chain of ubiquitin moieties is built up, connected to each other and to the substrate through isopeptide bonds (Hershko and Ciechanover, 1992; Ciechanover, 1994). This poly-ubiquitin protein conjugate is recognized as a substrate and degraded by a proteolytic complex known as the $26 \mathrm{~S}$ proteasome. This is a large multisubunit particle which is made up of two distinct subcomplexes, the 20S catalytic core and the 19S regulatory cap (Hershko and Ciechanover, 1992; Lupas et al., 1993; Rechsteiner et al., 1993; Tanahashi et al., 1993; Yoshimura et al., 1993; Peters, 1994). The 20S core particle contains 14 different subunits, classified into $\alpha$ and $\beta$ types, which are arranged in four seven-membered rings (Groll et al., 1997). The proteasome possesses several different peptide cleaving activities and the active sites for these are formed by the N-terminal threonine residues of some of the $\beta$ subunits (Chen and Hochsstrasser, 1996; Schmidtke et al., 1996; Seemuueller et al., 1996; Heinemeyer et al., 1997). Results from studies of the crystal structures of the 20S proteasome from Thermophillus acidophilum and Saccharomyces cerevisiae suggest that substrates have to be fully unfolded and translocated into the core particle for degradation. In the case of T.acidophilum, there are very narrow openings at either end of the 20S core particle (Lowe et al., 1995). With the yeast 20S proteasome, however, there is no such channel, a finding which suggests that the channel is gated, presumably by association with the 19S cap complex (Groll et al., 1997).

The unfolding of substrates and their translocation into the catalytic core of the proteasome is thought to be carried out by the 19S cap complex, also known as PA700, the $\mu$ particle or the regulatory particle (Dubiel et al., 1995; Tanaka and Tsurumi, 1997). The 19S cap consists of a number of different subunits. Recent biochemical characterizaiton of this subcomplex in S.cerevisiae revealed that it contained 17 different proteins (Glickman et al., 1998). These subunits fall into two classes. First, six subunits are members of a family of ATPases and it has been proposed that they function as reverse chaperones, unfolding substrates and translocating them into the catalytic core (Ghislain et al., 1993; Gordon et al., 1993; Dubiel et al., 1995; Fujiwara et al., 1996). The remaining 
proteins are termed the non-ATPases. Their role is less clear but proposed functions also include unfolding of substrates as well as recognition and the recycling of ubiquitin moieties. In this regard, an isopeptidase activity has been found associated with the 19S cap complex (Lam et al., 1997). Furthermore, one of the non-ATPase subunits, S5a, has been shown to recognize poly-ubiquitin chains in vitro (Deveraux et al., 1994). Deletion of the corresponding S.cerevisiae gene MCB1, however, was not a lethal event, suggesting that other factors can play a role in substrate recognition (van Nocker et al., 1996). Interestingly, mutations in the genes encoding the 19S cap subunits in both budding and fission yeasts display a diverse range of phenotypes, perhaps reflecting additional roles for the individual 19S cap subunits in substrate recognition (Gordon et al., 1993, 1996; DeMarini et al., 1995).

The 26S proteasome has been found in both the cytoplasm and nucleus of higher eukaryotic cells (Peters et al., 1994; Palmer et al., 1996). In immortalized granulosa cells, an increased concentration of proteasomes was found in mitotic as opposed to interphase nuclei (Amsterdam et al., 1993). There is also a striking nuclear accumulation of proteasomes in rapidly dividing cells in the early stages of Drosophila embryogenesis (Klein et al., 1990). A study of human fibrosarcoma cells containing a green fluorescent protein (GFP)-tagged interferon $\gamma$-inducible subunit LMP2, revealed that the proteasomes could diffuse rapidly but were also transported, albeit very slowly, unidirectionally from the cytoplasm into the nucleus. This study also showed that the GFP-tagged proteasomes could reach the nucleus by diffusion during mitosis when the nuclear membrane had broken down (Reits et al., 1997).

Previously, there has been no detailed analysis of the localization of proteasomes in either budding or fission yeast. We were therefore particularly interested to determine the distribution of the $26 \mathrm{~S}$ proteasome in fission yeast, especially as yeast undergoes a closed mitosis with no breakdown of the nuclear membrane. Immunofluorescence studies of fission yeast cells using antiserum against either the 19S cap subunit, Mts4 (Wilkinson et al., 1997), the whole 20S core complex or against a functional hemagglutinin (HA)-tagged version of the Pad1 subunit (Penney et al., 1998) revealed a striking localization pattern. The proteasome was found to be localized predominantly at the nuclear periphery, both in interphase and throughout mitosis. This finding was confirmed using a fission yeast strain containing a functional GFP-tagged Pad1 protein. Electron microscopic (EM) analysis was performed to determine that the staining pattern corresponded to the inner side of the nuclear membrane. Intriguingly, during mating, the signal became more dispersed in meiosis I and then restricted to the area between the separating DNA in meiosis II before dispersing and then re-appearing around the nuclei of the four spores in the resulting ascus. This striking association of the $26 \mathrm{~S}$ proteasome with the nuclear periphery in interphase and mitosis suggests that this is a major site of protein degradation in yeast. The changes in localization in meiosis suggest that the spatial organization of protein degradation could play an important role in this part of the life cycle. The possible implications of these findings are discussed.

\section{Results}

The 265 proteasome is localized predominantly at the nuclear periphery

The intracellular localization of the $26 \mathrm{~S}$ proteasome has been the subject of a number of studies resulting in a variety of conclusions within the literature (see Discussion). In this study, the localization of the 26S complex in fission yeast was analysed by variety of techniques. First, antiserum against the Mts4 protein was used to stain wildtype fission yeast cells. The protein was found to localize predominantly around the nucleus in a punctate manner (Figure 1A-D). This localization was found not only in interphase cells but also throughout mitosis (as in yeast, the nuclear membrane does not break down during cell division). As the cells progressed through mitosis and the two nuclei separated, the staining remained around the area containing the two nuclei (Figure $1 \mathrm{C}$ and D). As very little background staining could be seen, the majority of the Mts4 protein appeared to be in this location.

Two control experiments were carried out to ensure that the staining was specific for the Mts4 protein. First, no staining was seen if pre-immune serum was used (data not shown). Secondly, spores resulting from a $m t s 4^{+} u r a 4$ D18/mts4:: rat $^{+}$ura4-D18 diploid were stained (Figure 1E and F). Within each tetrad of spores, two are deleted for the $m t s 4^{+}$gene but will be ura ${ }^{+}$. The remaining two spores are wild-type with respect to $m t s 4^{+}$but not $\mathrm{ura}^{-}$. Upon germination in media lacking uracil, only the $m t s 4:: u r a 4^{+}$spores can germinate. These spores elongate but become arrested in metaphase. The wild-type spores, however, are unable to germinate as they are ura $^{-}$and remain round. Upon staining the spores with anti-Mts4 antiserum and diamidinophenylindole (DAPI), a bright ring of punctate staining was seen around the nuclear area in the round wild-type spores (Figure $1 \mathrm{E}$ and F, arrowhead). In contrast, the mts $4:: u r a 4^{+}$cells were totally devoid of Mts4 staining (Figure 1E and F, arrow). This result indicated that the staining seen in the wild-type cells was specifically that of the Mts4 protein. Antiserum raised against the $20 \mathrm{~S}$ core of the complex were also used to stain cells and the same perinuclear pattern of punctate staining was seen, indicating that this localization is indicative of the whole 26S complex (Figure 2). The same results were obtained using either paraformaldehyde fixation (as shown in Figures 1 and 2) or with methanol or glutaraldehyde fixation (data not shown).

\section{Co-localization of Mts4 with Pad1}

The staining pattern observed for Mts4 was confirmed by the immuno-localization studies of another 19S cap subunit, namely Pad1. This previously described protein (Shimanuki et al., 1995) was recently identified as being a component of the 19S regulatory cap complex of the 26S proteasome in humans (Spataro et al., 1997), S.cerevisiae (Glickman et al., 1998) and Schizosaccharomyces pombe (Penney et al., 1998). A strain was generated that contained a HA-tagged version of the gene at the $\mathrm{padl}^{+}$chromosomal locus. This tagged version replaced the endogenous $\mathrm{padl}^{+}$gene. As padl ${ }^{+}$is an essential gene (Shimanuki et al., 1995), the HA-tagged version appeared to be fully functional as cells grew at a rate comparable to wild-type and appeared normal when 


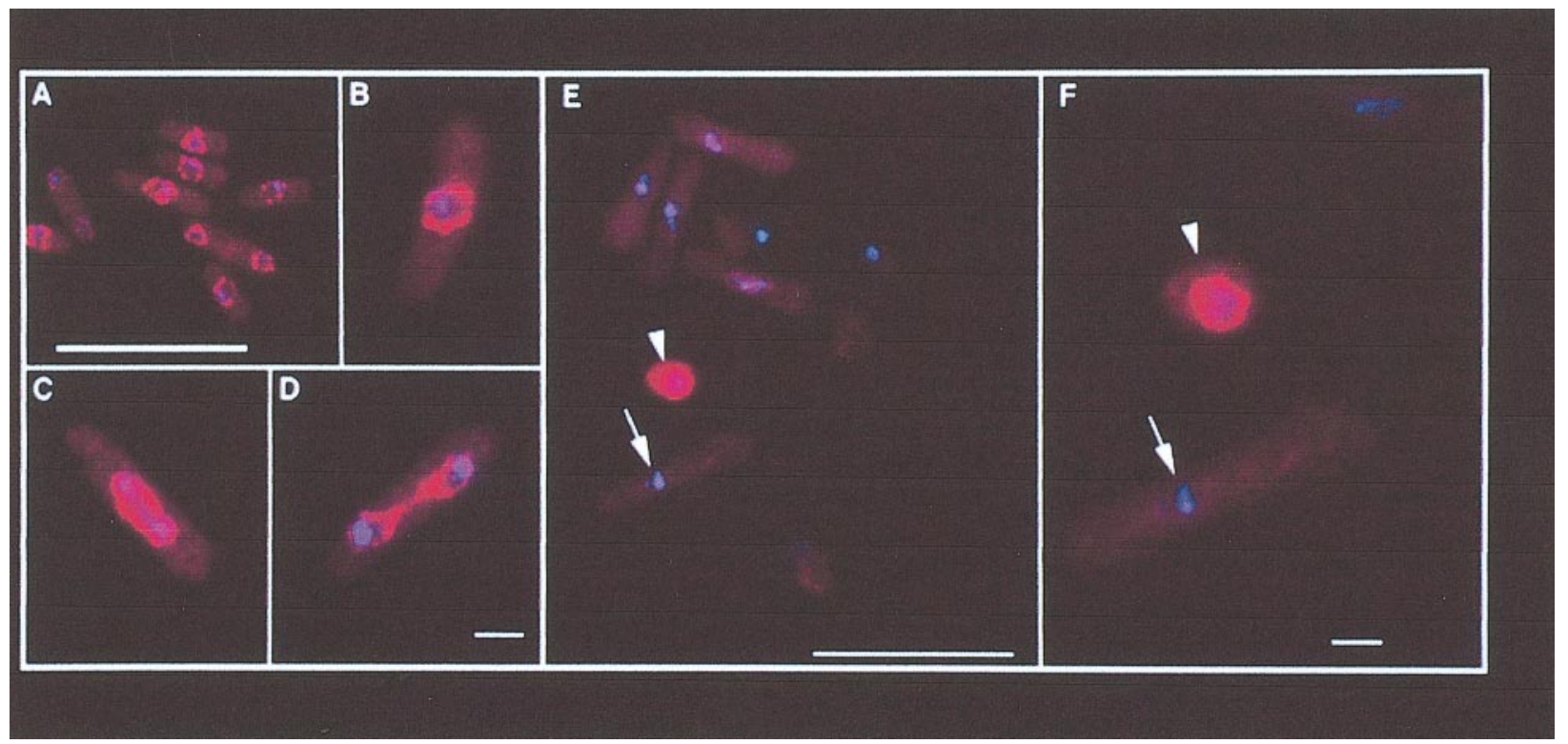

Fig. 1. Immunofluoresence microscopy to show the cellular localization of the Mts4 protein. (A-D) Wild-type S.pombe cells were fixed and stained with anti-Mts4 antiserum as described in Materials and methods. The DNA was stained with DAPI which appears blue; the anti-Mts4 antibodies were detected by a secondary antibody conjugated to CY3 which is shown as red. (B) An interphase cell. (C) A cell undergoing early anaphase. (D) A cell undergoing late anaphase. (E-F) The $m t s 4^{+} / m t s 4:: u r a 4^{+}$diploid was sporulated and the purified spores allowed to germinate in media lacking uracil. After $8 \mathrm{~h}$ cells were fixed and stained with DAPI and anti-Mts4 antiserum. The arrowhead indicates a spore which is wild-type with respect to $\mathrm{mts}^{+}$. The arrow indicates a $m t s 4:: u r a 4^{+}$cell. The bars in (A) and (E) represent $100 \mu \mathrm{m}$ while the bars in (D) and (F) represent $10 \mu \mathrm{m}$.

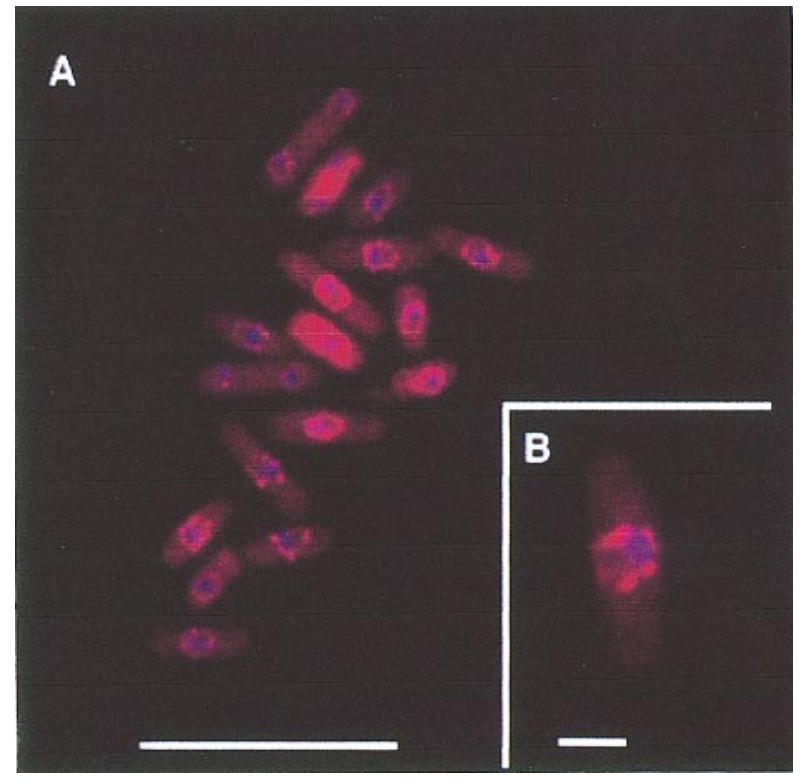

Fig. 2. Wild-type cells stained with DAPI and anti-20S antiserum. The bar represents $100 \mu \mathrm{m}$ in (A) and $10 \mu \mathrm{m}$ in (B). The DNA was stained with DAPI as for Figure 1 and the $20 \mathrm{~S}$ antiserum detected with a secondary antibody labelled with $\mathrm{CY} 3$ also as in Figure 1.

examined microscopically (data not shown). These cells were stained with antiserum against the Mts4 protein and monoclonal antiserum against the HA epitope (Figure 3a and $b$ ). Upon merging of the two images, the signal was found to be completely overlapping (Figure 3c) indicating that the two proteins co-localize, as expected for these two $26 \mathrm{~S}$ proteasome subunits.

\section{Co-localization of Mts4 with the nuclear envelope}

The staining pattern of the $26 \mathrm{~S}$ proteasome appeared to correspond to the nuclear periphery and therefore it was possible that the signal might correspond with that of the nuclear envelope. To address this possibility, wild-type cells were fixed and stained with both anti-Mts4 antiserum and monoclonal antibodies against the nuclear pore complex proteins (Rout and Blobel, 1993; Figure 4). Upon merging of the two signals, it can be seen that the two signals overlap, as indicated by the yellow signal seen in Figure 4d. These observations indicated that the staining seen with the antiserum against $26 \mathrm{~S}$ proteasomal components did indeed correspond to the nuclear periphery. It was not possible, however, from these data, to determine whether the $26 \mathrm{~S}$ proteasome is localized to the inner or outer side of the nuclear membrane. To address this question, EM analysis was carried out.

\section{Electron microscopic immunocytochemistry reveals that the 265 proteasome is localized to the inner side of the nuclear membrane in fission yeast}

The HA-tagged Pad1 subunit of the 26S proteasome was localized by immunogold staining of the $\mathrm{padl}^{+} \mathrm{HA}$ strain using monoclonal antibodies against the HA epitope. The HA signal localized specifically to the inner side of the nuclear membrane (Figure $5 \mathrm{~b}$ and $\mathrm{c}$ ). In contrast, no specific signal was seen in wild-type cells, containing the endogenous $\mathrm{padl}^{+}$gene only, that had been treated in an identical manner with antiserum against the HA epitope (Figure 5a). We have compared the strength of the signal in areas that appear to be well stained with gold in specimens treated with antiserum to HA with that of the background, or 'noise' by counting the number of gold particles per unit area in the same cell or with nuclear regions from cells that contained no HA epitope but which were processed for immuno-electron microscopy in the same way. The areas of signal bound 5.7 times as much gold as other areas in the same cell and 18.6 times as 


\section{C.R.M.Wilkinson et al.}
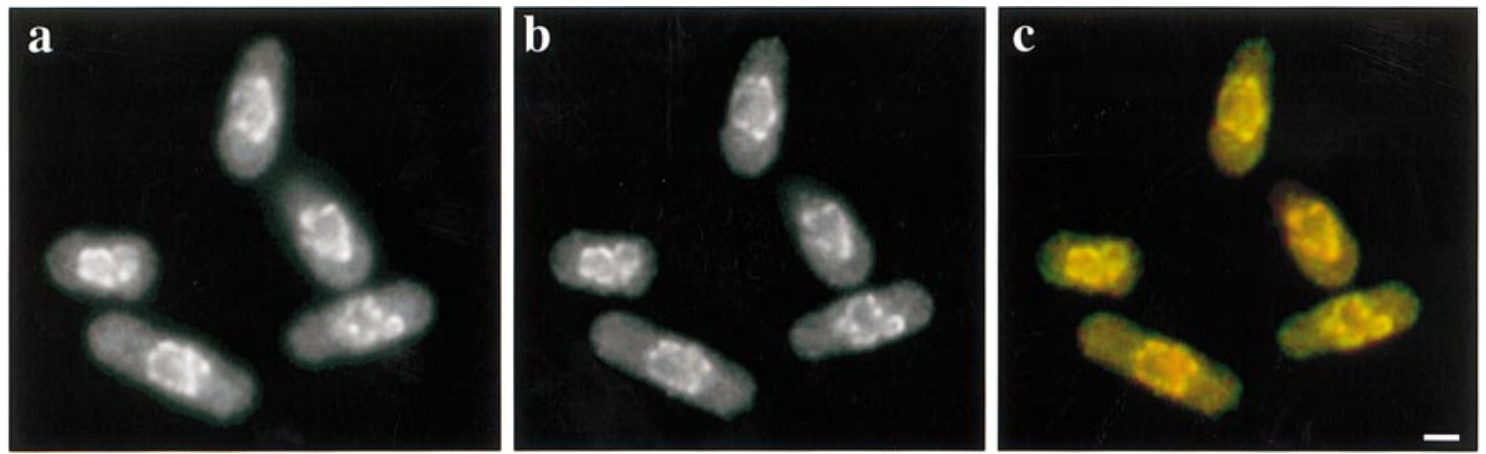

Fig. 3. Co-localization of Mts4 and Pad1. Pad1-HA-containing cells were fixed with paraformaldehyde and stained with antiserum against Mts4 (a) and the HA epitope (b). The Mts4 signal was visualized by FITC-labelled donkey anti-rabbit IgG and the Pad1-HA signal visualized by Texas Redconjugated goat anti-mouse IgG. The two images were merged and the resulting image is shown in (c).

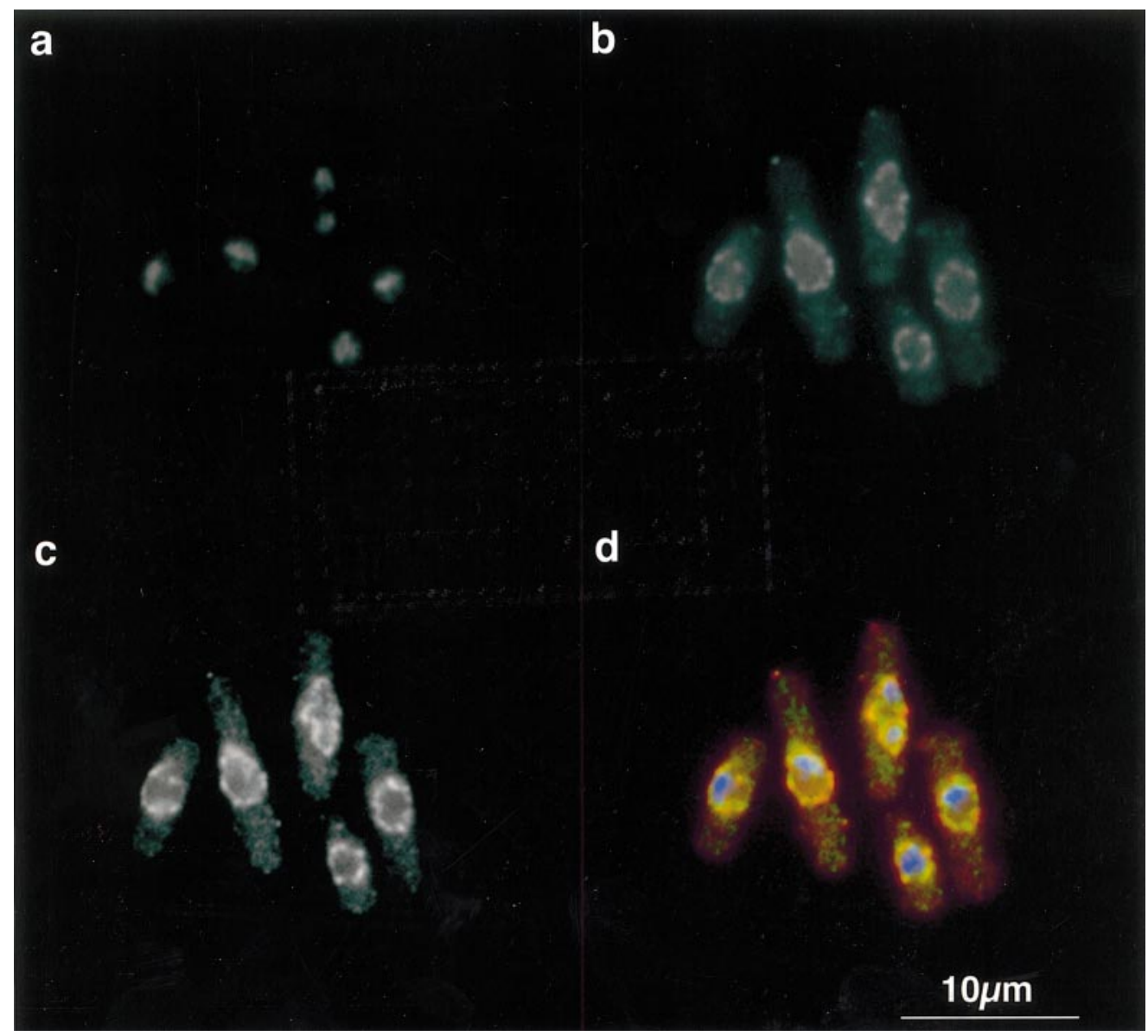

Fig. 4. Co-localization of Mts4 and the nuclear pore complex proteins. Cells were fixed in paraformaldehyde and stained with DAPI (a), with antisera against mAB414 (b) or Mts4 (c). The Mts4 signal was visualized by FITC-labelled donkey anti-rabbit IgG and the mAB414 signal visualized by Texas Red-conjugated goat anti-mouse IgG. The images were merged and the resulting image is shown in (d).

much gold as comparable regions in cells without the HA epitope, suggesting a specific staining. Furthermore, serial sections through a cell gave identical results (data not shown). Attempts were made to confirm this finding by staining wild-type cells with affinity-purified antiserum raised against the Mts4 protein. Unfortunately this proved unsuccessful presumably as none of the epitopes recognized by this antiserum survived our preparative methods for electron microscopy.

\section{Analysis of the distribution of the 26S proteasome in live cells}

The possibility existed that the results seen with immunofluorescence microscopy were artefactual due to the methods of fixation employed; therefore, we decided to analyse the distribution of the $26 \mathrm{~S}$ proteasome in live cells. A construct was generated to enable expression of a proteasome subunit fused to the reporter protein GFP. A fission yeast strain was generated that expressed a GFP- 

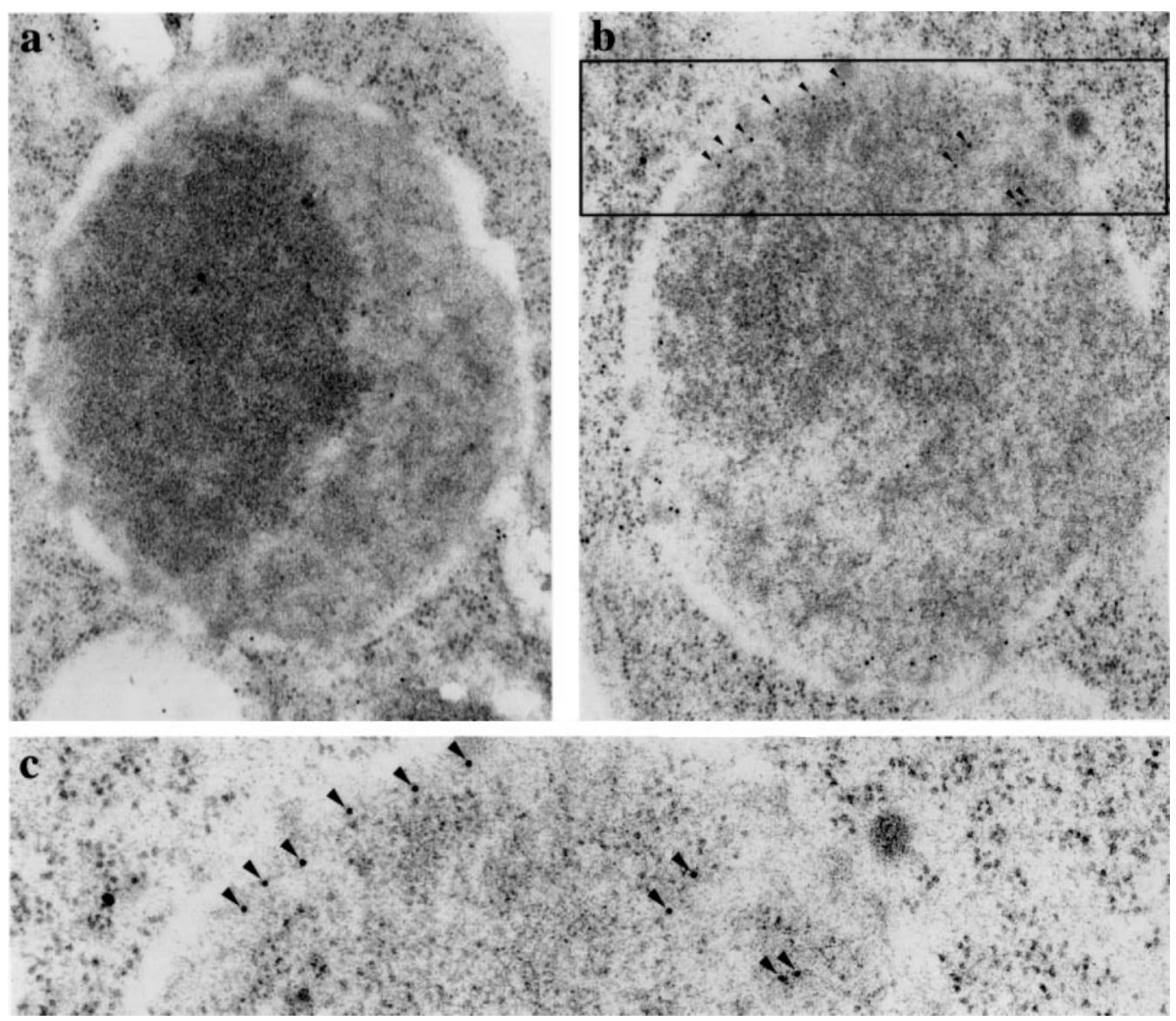

Fig. 5. EM localization of the Pad1 protein to the inner side of the nuclear membrane. Immunogold staining of a section through a wild-type cell (a) and Pad1-HA containing cell (b and $\mathbf{c}$ ) using antibodies to the HA epitope. Secondary antibodies were conjugated to $10 \mathrm{~nm}$ colloidal gold. The Pad1-HA protein was found to be localized to the inner side of the nuclear membrane [arrowheads in panels (b) and (c)].

tagged version of the $19 \mathrm{~S}$ cap subunit Pad1. The strategy for generating a chromosomal copy of the gfp-fused $\mathrm{padl}^{+}$ gene is shown in Figure 6A. A construct was made that created an in-frame fusion of the coding region for GFP immediately downstream of the C-terminal 171 codons of the $\mathrm{padl}^{+}$gene. A stop codon was included at the end of the gfp sequence and this was followed by $0.4 \mathrm{~kb}$ of $3^{\prime}$ untranslated $\mathrm{padl}^{+}$genomic sequence. This construct was cloned in pBluescript along with the $\mathrm{ura4}^{+}$selectable marker and then linearized at a unique SalI site in the $\mathrm{padl}^{+}$coding sequence. The resulting linear DNA was transformed into a ura ${ }^{-}$fission yeast strain and $\mathrm{ura}^{+}$ transformants selected. The insertion, by homologous recombination, of this fragment into the genome resulted in the production of the GFP-tagged Pad1 protein under the control of the endogenous padl ${ }^{+}$promoter. The correct insertion event was confirmed by genomic PCR and Southern blot hybridization (data not shown). As with the HA-tagged version of Pad1, the ability to isolate transformants containing the tagged version of the gene at the correct chromosomal locus was indicative of the tagged Pad1 protein being functional. The strain containing Pad1-GFP was found to grow at a similar rate to wildtype cells and appeared wild-type when examined microscopically (data not shown). These findings implied that the Pad1-GFP protein was behaving as the wild-type protein but it was important to demonstrate that the fusion protein was being incorporated into the $26 \mathrm{~S}$ proteasome.
When glycerol gradient centrifugation analysis is used to partially purify the $26 \mathrm{~S}$ proteasome from cellular extracts, the complex is found to migrate with a particular profile (Kominami et al., 1995, 1997; Seeger et al., 1996). Cellular protein extracts were prepared from the Pad1GFP strain and run through a 10-40\% glycerol gradient. Fractions from the gradient were analyzed by Western blotting. As shown in Figure 6B, known components of the $26 \mathrm{~S}$ proteasome such as the $20 \mathrm{~S}$ core complex and the 19S cap subunit were found predominantly in fractions 13-15 corresponding to the more rapidly sedimenting end of the gradient. The Pad1-GFP fusion protein was assayed by probing the extracts with anti-GFP antibodies. A band of the predicted size for the fusion protein $(62 \mathrm{kDa})$ was recognized and its profile found to match that seen for the known components of the proteasome, that is, also predominantly in fractions $13-15$. This indicated that the Pad1-GFP fusion protein was migrating with known components of the proteasome. Moreover, immunoprecipitates of fission yeast protein extracts using anti-Mts4 antiserum were found to contain the Pad1-GFP protein providing further evidence that the Pad1-GFP protein is incorporated into the proteasome (data not shown).

The distribution of the $26 \mathrm{~S}$ proteasome was analysed in live cells. As seen in Figure 6C, the signal was predominantly concentrated around the nuclear periphery, thus confirming the results seen with immunofluorescence microscopy. Furthermore, the staining was not continuous, 


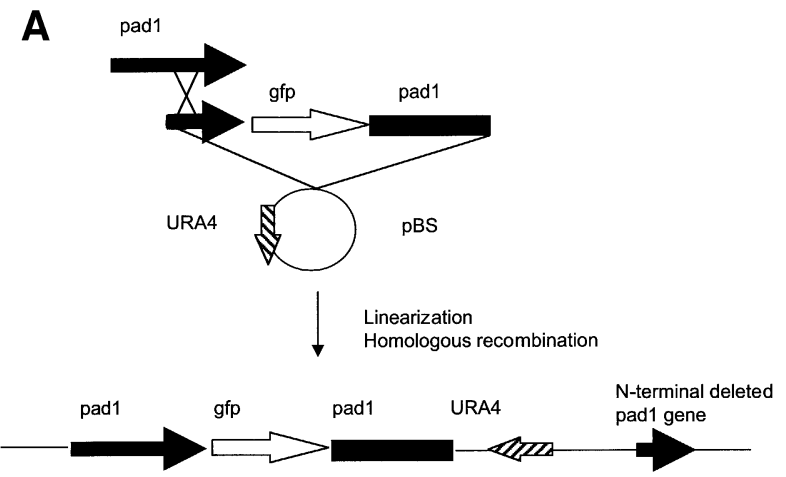

B
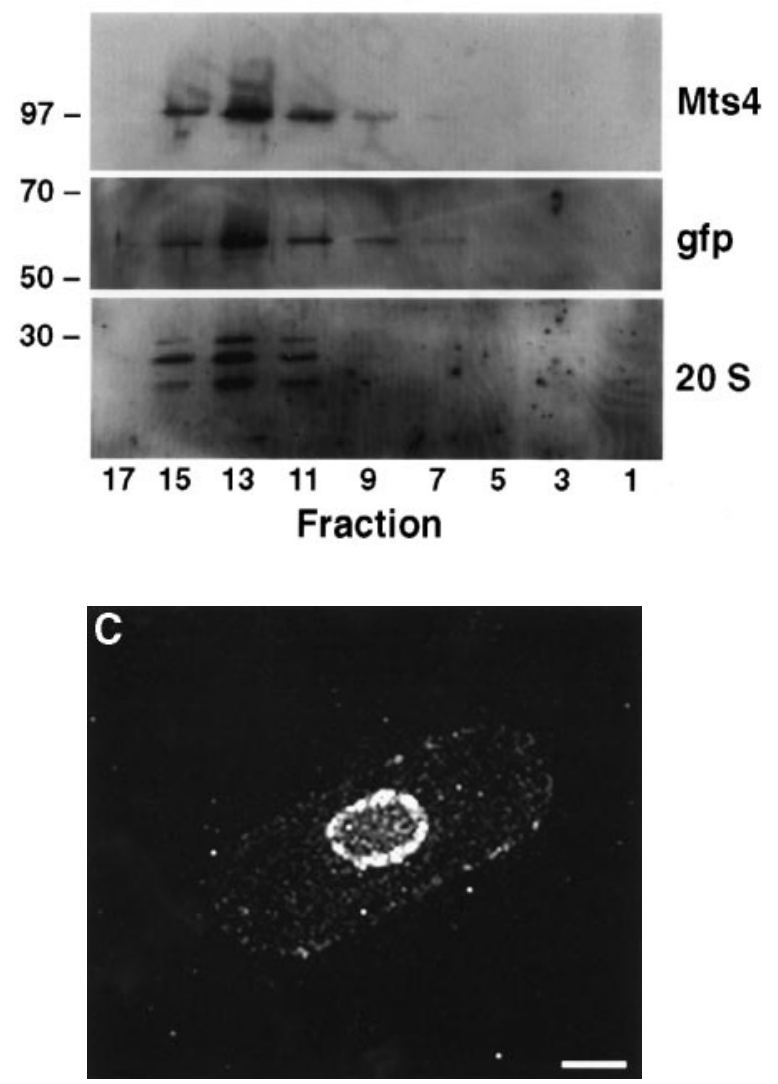

Fig. 6. Analysis of $26 \mathrm{~S}$ proteasome localization within live fission yeast cells. (A) Strategy for constructing the Pad1-GFP fusion protein. The wild-type $\mathrm{padl}^{+}$gene was replaced with a version fused to the gfp open reading frame by homologous recombination. (B) Western blot analysis of Pad1-GFP-containing protein extracts separated by $10-40 \%$ glycerol gradient centrifugation. Equal amounts of proteins from alternate fractions of the gradient were separated by $12 \%$ SDSPAGE and blotted onto nitrocellulose and probed with the antibodies shown. Fraction 17 and fraction 1 correspond to the most and least rapidly sedimenting parts of the gradient respectively. (C) Cells containing the Pad1-GFP fusion protein were analyzed by fluorescence microscopy. Scale bar, $10 \mu \mathrm{m}$.

but was more punctate in nature, again confirming the data seen with fixed cells. A faint cytosolic staining was also observed which is not as apparent from the immunofluorescence data, possibly due to the loss of this signal during fixation. This staining is spread over the cytosol but is excluded from the vacuoles.
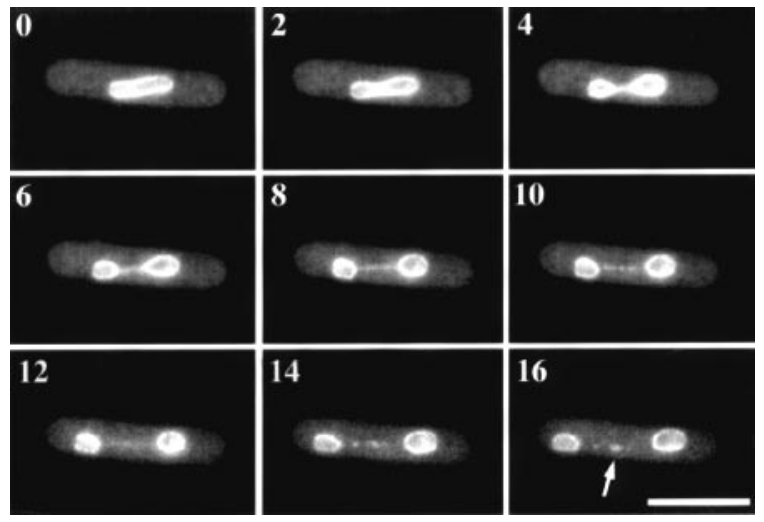

Fig. 7. Live-cell analysis of $26 \mathrm{~S}$ proteasome localization during mitosis. Fluorescence images were obtained at the times indicated in minutes. Arrow shows the small blob of GFP-signal found equidistant between the two dividing nuclei. Scale bar, $10 \mu \mathrm{m}$.

\section{Localization of the 265 proteasome in live cells undergoing mitosis}

During the examination of fixed cells by immunofluorescence using the anti-Mts4 antiserum, we observed that the signal remained associated with the nuclear periphery during anaphase. We decided to investigate this in more detail using the $p a d l^{+}-g f p$ strain. Live cells undergoing mitosis were observed by fluorescence microscopy. Cells were exposed for $1 \mathrm{~s}$ every $30 \mathrm{~s}$ and the images were stored as a multifile which could be run as an animation. Figure 7 shows a cell undergoing mitosis. As shown previously (Figure 6C), the GFP signal was predominantly found at the nuclear periphery. Intriguingly, as the two nuclei separated during late anaphase, a trail of staining was observed between them (Figure 7). This trail gradually disappeared leaving a blob of staining equidistant between the two nuclei (Figure 7, arrow). This small, but presumably highly concentrated region of proteasomes, was consistently observed in all late anaphase cells examined.

\section{Localization of the 265 proteasome in live cells undergoing meiosis}

Following on from the observations made in mitosis, we were interested to investigate the distribution of proteasomes in cells undergoing mating. In fission yeast, haploid cells of the opposite mating type conjugate upon nitrogen starvation and enter the meiotic cycle. The cells first undergo karyogamy (nuclear fusion), followed by premeiotic 'horsetail' movement during meiotic prophase. During this stage, the cells display an elongated nuclear morphology. Observations of live cells at this stage revealed that there is considerable movement of the nuclei and it is believed that this is concomitant with the association and recombination of homologous chromosomes (Chikashige et al., 1994). This stage is then followed by the first and second meiotic divisions. Matings were carried out using the homothallic $p a d l^{+}-g f p h^{90}$ strain. During karyogamy and horsetail movement, the proteasome distribution was found to dissociate from the nuclear periphery and become distributed over the whole nucleus (Figure 8A and B). No signal was observed in the nucleolus. During horsetail movement, however, a small bright spot of staining was always observed at the edge of the nucleus (Figure 8B, arrow). During horsetail 
A

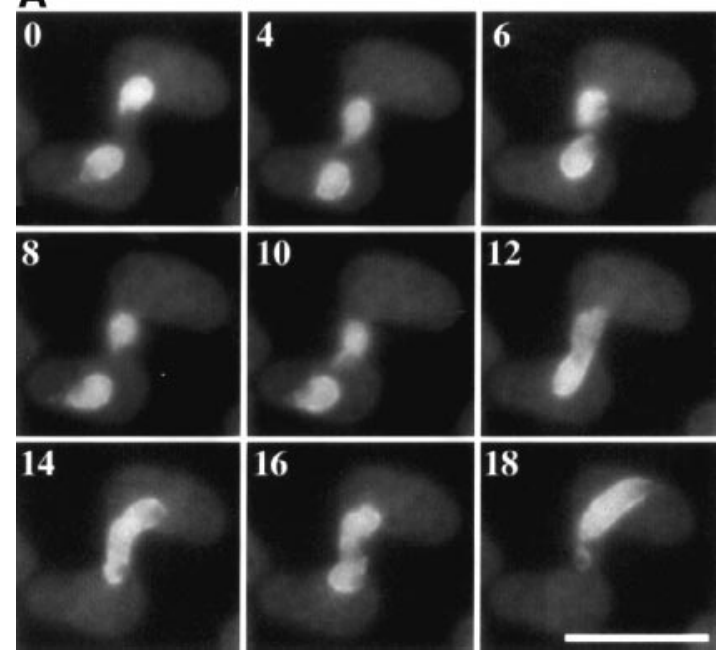

B
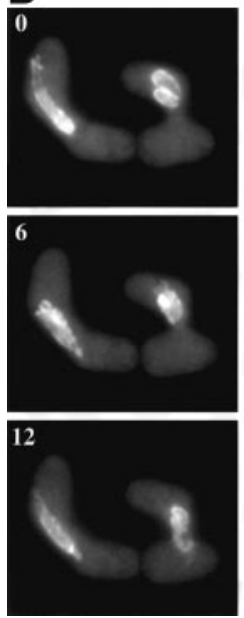
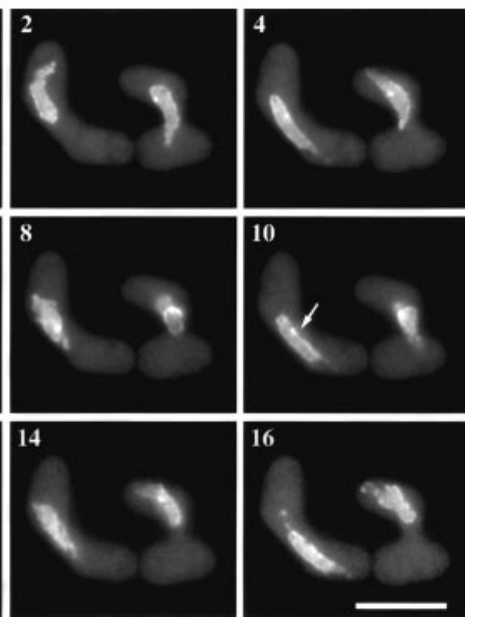

E
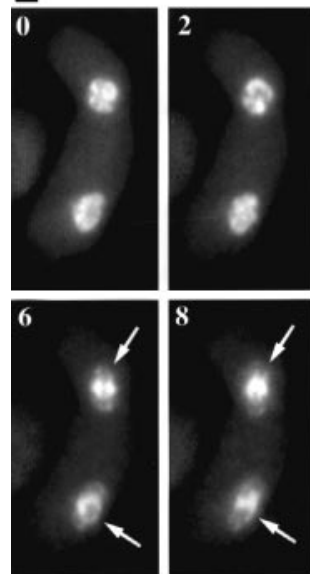

12

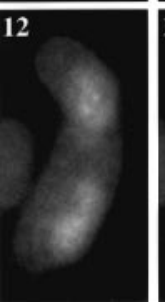

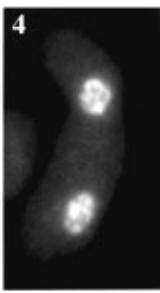

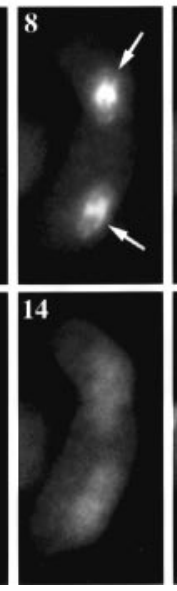

10

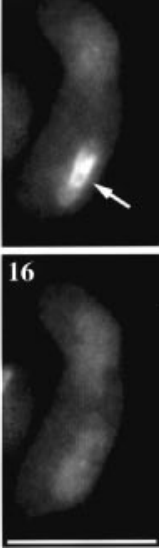

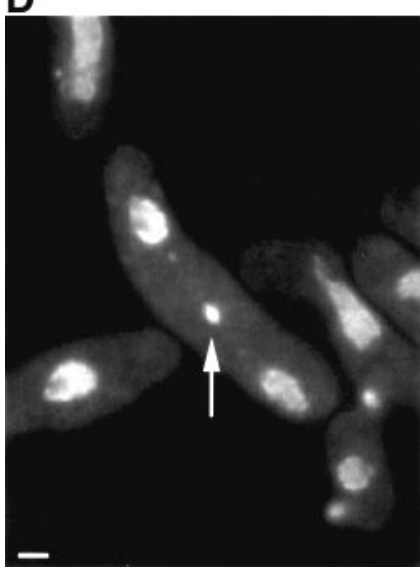

$\mathbf{F}$
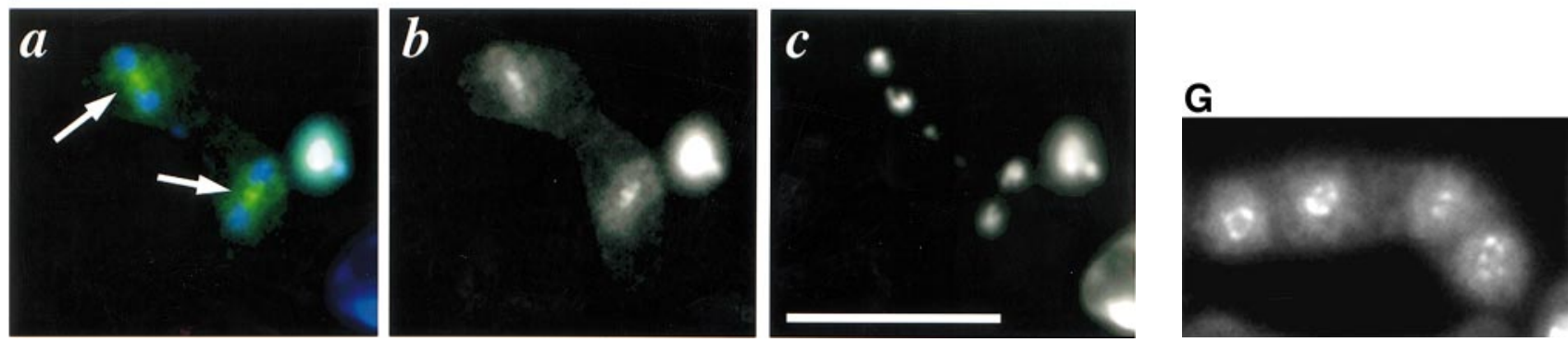

Fig. 8. Live-cell analysis of the $26 \mathrm{~S}$ proteasome localization during different stages of mating. Fluorescence images were obtained at the times shown in min. Scale bar, $10 \mu \mathrm{m}$. (A) Karyogamy. (B) 'Horsetail' movement. The arrow indicates the bright spot of staining observed during this stage of meiosis. (C and D) Meiosis I. In (D) the arrow indicates a bright spot of staining between the two nuclei. (E) Meiosis II. The arrow indicates the bright staining observed as cells proceed through meiosis II. (F) DNA and GFP staining of cells in meiosis II. Cells were labelled with the DNA-specific stain Hoechst $33342(c)$, GFP $(b)$ and the two images merged $(a)$. The arrow shows GFP staining is located between the separating DNA in the merged image. (G) Ascus. The 26S proteasomes re-localize to the nuclear periphery upon spore formation. 
movement, the telomeres and spindle-pole bodies are clustered at the leading edge of the nuclear movement. As the bright spot of staining was observed away from the leading edge, it would not appear to be associated with the telomeres or spindle-pole bodies. The localization of the proteasome during meiosis I can be seen in Figure $8 \mathrm{C}$. The staining observed was very similar to that found for mitosis. Once again during late anaphase, a bright spot of staining was seen midway between the two separating nuclei (Figure 8C and D). During meiosis II, however, a dramatic re-organization of proteasome distribution occurred (Figure 8E). As meiosis II proceeded, the proteasome signal moved from being found all over the nucleus to a restricted region at the centre of the dividing nucleus (Figure 8E, arrow). Staining the DNA of these nuclei with Hoechst 33342 demonstrated that the GFP signal was localized to the region between the separating DNA (Figure 8F). At the end of meiosis II the intense signal disappeared suddenly and remained diffuse until the spores formed (Figure 8G). Upon spore formation, the proteasomes re-localized and displayed the punctate nuclear peripheral staining previously observed in mitotic cells.

\section{Discussion}

Previous studies regarding the localization of the $26 \mathrm{~S}$ proteasome in higher eukaryotes have led to conflicting results. Many reports provide evidence for localization of the complex to both the nucleus and cytoplasm where it is found in rather a disperse form (Rivett et al., 1992; Peters et al., 1994). Some studies have found that a certain fraction of proteasomes were associated with ER membranes (Rivett et al., 1992; Yang et al., 1995). Other studies, however, provide evidence in favour of preferential localization to certain nuclear sub-structures such as intermediate filaments (Grossi de Sa et al., 1988; Pal et al., 1988). Some researchers report that the complex is found almost exclusively in the nucleus (Stauber et al., 1987) or the cytoplasm (Kloetzel et al., 1987, Beyette and Mykles, 1992). Interestingly, changes in localization have been reported during mitosis (Amsterdam et al., 1993) and also during development (Akhayat et al., 1987; Pal et al., 1988; Klein et al., 1990). It has been suggested that the association of the $26 \mathrm{~S}$ proteasome with various nuclear structures or restriction to the cytoplasm may reflect artefactual retention of the complex during sample preparation (Peters et al., 1994; Reits et al., 1997). An alternative explanation for such conflicting results is that they represent the varying nature of the localization of the $26 \mathrm{~S}$ complex in a variety of cell types in a number of different organisms.

We have clearly demonstrated that in fission yeast, the $26 \mathrm{~S}$ proteasome is localized predominantly at the nuclear periphery. First, we demonstrated this by immunofluorescence using antiserum to two different 19S cap subunits and antiserum against the whole $20 \mathrm{~S}$ complex. It appears from these results that there is very little cytoplasmic staining; however, this is probably due to the fixation of the cells as analysis of the Pad1-GFP-tagged proteasomes clearly indicates that the proteasomes are also found in the cytoplasm of fission yeast cells. We have also tagged the Mts3 protein (which is another component of the $19 \mathrm{~S}$ regulatory cap; Gordon et al., 1996) with GFP and we see the same perinuclear signal (data not shown) providing further confirmation that the pattern that we see is correct. Studies in S.cerevisiae have revealed that abnormal proteins in the ER are transported to the cytoplasm by ER translocons and the chaperone Kar2/Bip (Hiller et al., 1996; Plemper et al., 1997). The $26 \mathrm{~S}$ proteasome has been shown to be involved in the degradation of these substrates. As we observe the $26 \mathrm{~S}$ proteasome in the cytoplasm as well as the high concentration around the nuclear periphery, especially with the GFP-tagged strains, our data is consistent with these findings.

EM analysis was used to show that the staining pattern seen corresponded to the inner face of the nuclear membrane. It was not possible to use any further antibodies against other subunits to confirm this finding. This is unfortunate but not surprising as approximately half of the antibodies tested at the Boulder Lab for three dimensional fine structure fail to recognize their antigens after the EM preparations used here (M.M. and J.R.M., unpublished data). However, the Pad1-HA data do identify the side of the nuclear envelope at which the proteasome is concentrated. It would be interesting to determine the nature of this accumulation at the nuclear membrane. For example, are the proteasomes being anchored to a particular structure? Is there a direct or even a functional association with the nuclear pore complex? A further question relates to the nature of the punctate signal. Is this due to high local concentrations of the complex?

A previous report has shown that in S.cerevisiae, the Sug2/Pcs1 19S cap subunit is localized to the whole nucleus (McDonald and Bryers, 1997). A similar result was found with the HA-tagged Sen3 subunit. This is clearly different to our findings. One possible explanation is that in the Pcs1 study, the GFP-Pcs1 fusion protein was expressed from a plasmid, albeit with the PCS1 promoter. The HA-tagged Sen3 subunit was also expressed from a plasmid. In our studies, we have found that expression from plasmids, even to levels only slightly higher than wild-type, results in an increase in signal over the whole nucleus. For this reason, we chose to study the distribution of the proteasome in cells containing an integrated version of the Pad1-GFP fusion construct expressed from the $\mathrm{padl}^{+}$promoter.

During studies using GFP-tagged proteasomes in fibrosarcoma cells, it was found that proteasomes could diffuse into the nucleus during mitosis as the nuclear envelope was no longer intact (Reits et al., 1997). In addition the proteasome was also found to be transported unidirectionally over the nuclear membrane from the cytoplasm to the nucleus. The dimensions of the yeast $20 \mathrm{~S}$ proteasome were found to be $113 \times 148 \AA$. As the channel in the nuclear pore has been calculated to be $260 \AA$ in diameter (Felddherr et al., 1984; Gerace, 1992) this would permit the transport of the proteasome as a complete complex without mass perturbations to its structure. Putative nuclear localization signals (NLSs) have been found in the $\alpha$ subunits of the 20S core complex (reviewed in Tanaka et al., 1990) and thus it seems likely that this is how the proteasomes enter the nucleus. These 20S NLSs have been found to direct reporter proteins to the nucleus in in vitro assays but their in vivo relevance has yet to be demonstrated (Nederlof et al., 1995; Knuehl 
et al., 1996). What is not so clear is what determines how some of the proteasomes remain in the cytoplasm and what targets the complex specifically to the nuclear periphery. One way of addressing these questions is to look for fission yeast mutants in which the proteasome is mislocalized. Future work will utilize screens designed to isolate such mutants.

We have shown that the concentration of the proteasome at the nuclear periphery persists throughout mitosis. It is not possible to remove out-of-focus haze in these images as was achieved for the image seen in Figure 6C, but it is still very clear that the majority of the proteasome is found at the nuclear periphery. Intriguingly, there is a concentrated spot of staining that is seen as the two daughter nuclei pull apart. This could be explained by a residual pool of proteasomes remaining in this location after the nuclear envelope separates to surround the two daughter nuclei. Alternatively, it may be that this patch of proteasomes is specifically localized to this position to participate in the regulation of spindle disassembly or perhaps in the control of events that regulate cytokinesis. Interestingly, a cell-cycle-dependent change in the distribution of nuclear proteasomes has been observed in higher eukaryotes. The localization of the proteasome was followed throughout mitosis during the embryonic development of the ascidian Halocynthia roretzi (Kawahara and Yokosawa, 1992). In interphase, proteasomes were found in the nucleoplasm and along the nuclear membrane. During metaphase, the proteasome was found to colocalize with chromosomes and the spindle. This staining was lost during anaphase. Changes of proteasome distribution were also observed during mitosis in immortalized ovarian granula cell lines. Proteasomal staining was found in small clusters throughout the nucleus. As cells proceeded through mitosis, the staining increased in the perichromosomal area. Interestingly, staining was also seen around the spindle fibres in anaphase.

In meiosis, we observed the same pattern of staining but during the horsetail movement that follows karyogamy and meiotic DNA synthesis, there is a bright spot in the nucleus. A number of proteins have been identified whose degradation is required for cells to proceed through the cell cycle (King et al., 1996). It is highly possible that the events of meiosis are similarly controlled by proteolysis. It will be interesting to see if the localization of such proteins, once identified, match that of the intense proteasomal staining that we have observed at this stage of meiosis. The subsequent dispersal of the complex throughout the nucleus during meiosis II is perhaps an indication that the proteasome is not necessarily rigidly anchored at the nuclear periphery. Perhaps the re-localization occurs in meiosis II so that the proteasomes can catalyze proteolytic events specifically aimed towards controlling spore formation.

The predominant localization of the $26 \mathrm{~S}$ proteasome at the nuclear periphery in fission yeast suggests that this is the major site of protein degradation in these cells. This would seem to imply, therefore, that substrates might have to be targeted to this part of the nucleus for degradation. Alternatively, substrates might simply encounter the proteasome by diffusing through the nucleoplasm until they reach the periphery. The low level Pad1-GFP staining throughout the cytosol is also consistent with this latter proposal. This is different to the observations made in HT1080 fibrosarcoma cells where the proteasomes were found to diffuse freely and were found distributed throughout the cytoplasm and nucleoplasm. One interesting possibility is that the poly-ubiquitin tail could act as a targeting mechanism rather that solely as a signal for degradation. To date, only one subunit of the $26 \mathrm{~S}$ proteasome, namely S5a, has been found to bind poly-ubiquitin chains (Deveraux et al., 1994). Interestingly, a substantial proportion of this subunit is found in a free form and not associated with the proteasome in both budding yeast and Drosophila (Haracska and Udvardy, 1995; van Nocker et al., 1996). Perhaps a role for this additional S5a is to act as a shuttling factor taking substrates to the proteasome at the nuclear periphery. The use of mutations in proteasomal components and analysis of known substrates in these mutant backgrounds should help in the effort to answer some of these questions. One possible role for the high concentration of proteasomes at the nuclear periphery is to monitor the vast amount of traffic that passes between the nucleus and cytoplasm every minute. Our knowledge of the mediators and receptors of this transport has increased greatly in recent years (reviewed in Ohno et al., 1998; Pemberton et al., 1998; Weis, 1998). Receptors for trafficking could also act as shuttling factors taking substrates to the proteasomes. Work is in progress to try and elucidate the answers to some of these intriguing possibilities.

\section{Materials and methods}

\section{Pombe strains and techniques}

All S.pombe strains used were derived from the wild-type heterothallic strains $972 h^{-}$and $975 h^{+}$. Standard genetic manipulations and media were as described (Moreno et al., 1991). Yeast transformations were performed by electroporation (Prentice, 1991). The $m t s 4^{+}$ura4-D18/ mts $4:$ ura $^{+}{ }^{+}$ura4-D18 diploid was generated as described (Wilkinson et al., 1997).

\section{Generation of HA- and GFP-tagged constructs}

The $\mathrm{pad} 1^{+} \mathrm{HA}$ strain was made by incorporating a NotI site just before the stop codon of the $\mathrm{padl}^{+}$gene using the following PCR primers: nmt84 5'-CCTGGCATATCATCAATT-3' and 5'-AAGGCCTAGCGGCCGCAGAAGGCAACGGAATCAAGCATACAAGC- $3^{\prime}$. The resulting PCR product was cut with XhoI-SmaI and cloned into pREP3X (Maundrell, 1993). A 111 bp $3 \times$ HA NotI fragment was cloned into the NotI site of pREP3Xpad $1^{+}$to create the plasmid pREPpad1HA which has a HAtagged version of the $\mathrm{padl}^{+}$gene under the control of the thiamine repressible promoter (Maundrell, 1993). A 909 bp EcoRI-ScaI fragment containing the $\mathrm{padl}^{+} \mathrm{HA}$ gene was excised from pREPpad1 ${ }^{+} \mathrm{HA}$ and cloned into pUC19ura4SphI (pUC19 carrying $\mathrm{ura}^{+}$at the SphI site). The resulting plasmid was linearized using the remaining SmaI site and transformed into the fission yeast strain SP813 (leul-32ade6M210ura4D-18) and $\mathrm{URA}^{+}$transformants selected. This created strain pad1 ${ }^{+} \mathrm{HA}$ (leu1-32ade6-M210ura4-D18pad1 ${ }^{+} \mathrm{HA}$ ) which has the pad1 ${ }^{+}$ gene tagged with HA and under the control of the endogenous $\mathrm{padl}^{+}$ promoter.

In order to make a $\mathrm{pad1}^{+}$-GFP fusion construct, the pUC18 vector was first manipulated to remove the EcoRI and SalI sites. The vector was digested with these enzymes followed by Klenow treatment and religation to create vector pMW1. A HindIII fragment containing the ura $^{+}$gene was then ligated into the HindIII site of pMW2 to give pMW3. The pad1 ${ }^{+}$gene was amplified by PCR using the following oligonucleotides N709 (incorporating a $B g l$ II site): 5'-GCGCAGATCTCACCAAGAGCGGTGGCAGTT N710: 5'-GCTAGGATCCTGAGAATTCATCCATGGCAGGCCTGAAGGCAACGGAATCAAGCATACAAG (BamHI, EcoRI, NcoI, StuI, followed by pad ${ }^{+}$sequence). The resulting PCR product was digested with BamHI and $B g l \mathrm{II}$ and ligated to pMW3 that had been digested with BamHI. This gave the plasmid 
pMW4 which contains the region of the $\mathrm{padl}^{+}$gene that corresponds to codons 137-308 out of a total of 308 codons (not including the stop codon). The $3^{\prime}$ untranslated region of the $\mathrm{padl}^{+}$gene was amplified by PCR using the following oligonucleotides: N970 (incorporating a Bam $\mathrm{HI}$ site): 5'-GCGCGGATCCTACATCTATTTTGGTAATACCTCTTTTCCATCATCCGTTTTTTATGAGC $($ Bam $\mathrm{HI})$ and N971 (incorporating an SphI site): 5'-ACATGCATGCTGGTTTGACGCTGATCGACGATCC. The resulting DNA was digested with SphI and Bam HI and ligated to pMW4 that had also been digested with these two enzymes. The resulting plasmid was called pMW6. This plasmid was linearized by digesting with SalI which cut at a unique site within the $\mathrm{padl}^{+}$coding sequence and the resulting DNA transformed into the wild-type fission yeast strain leu1-32ura4D-18h-. Transformants that were $\mathrm{ura}^{+}$were selected and colonies arising from integration of the pMW6 DNA at the pad1 locus confirmed by genomic colony PCR and Southern analysis.

\section{Glycerol gradient centrifugation}

One litre of cells containing the $p a d 1^{+}-g f p$ fusion gene were grown to an $A_{595}$ of 0.8 and harvested by centrifugation. The resulting cell pellet was resuspended in $3 \mathrm{ml}$ of the following buffer: $10 \%$ glycerol, $50 \mathrm{mM}$ Tris $\mathrm{pH} 7.5,2 \mathrm{mM}$ ATP, $5 \mathrm{mM} \mathrm{MgCl}_{2}, 5 \mu \mathrm{g} / \mathrm{ml}$ pepstatin A, $5 \mu \mathrm{M}$ leupeptin, $1 \mathrm{mM}$ phenylmethyl sulphonylfluoride (PMSF) and the cells were lysed with glass beads and vortexing. The extracts were clarified by centrifugation at 13000 r.p.m. for $30 \mathrm{~min}$ at $4^{\circ} \mathrm{C}$. Thirty milligrams

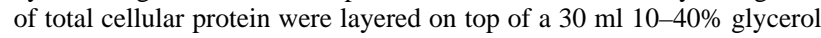
gradient which was then spun for $24 \mathrm{~h}$ at 27000 r.p.m. at $4^{\circ} \mathrm{C}$. Twomillilitre fractions were collected from the top and equal amounts of protein from alternate fractions were analysed by Western blotting. Western blot analysis was carried out as described (Wilkinson et al., 1997). The following antisera were used as follows for Western blot analysis: Anti-Mts4 (Wilkinson et al., 1997), diluted 1 in 5000; anti20S core complex (Seeger et al., 1996), diluted 1 in 1000; anti-GFP (Clontech) diluted 1 in 500. Mts4 antiserum was affinity purified using recombinant Mts 4 protein on a nitrocellulose strip and incubating $200 \mu \mathrm{l}$ of antiserum for $2 \mathrm{~h}$ at room temperature in $800 \mu \mathrm{l}$ of TBS. After several washes in TBS-0.05\% Tween-20, the bound antiserum was eluted in $300 \mu \mathrm{l}$ of $200 \mathrm{mM}$ glycine, $\mathrm{pH} 2.5$, with $0.1 \%$ bovine serum albumin (BSA) for $30 \mathrm{~min}$. This was neutralized with $30 \mu \mathrm{l} 1 \mathrm{M}$ Tris and dialysed against TBS for $10 \mathrm{~min}$.

\section{Immunofluorescence microscopy}

DAPI staining was as described (Toda et al., 1981). For immunofluorescence microscopy, cells were grown overnight in yeast extract and immediately before fixation, sorbitol was added to the culture to give a final concentration of $1.2 \mathrm{M}$. The cells were then fixed in $3.8 \%$ paraformaldehyde at $32^{\circ} \mathrm{C}$ for $30 \mathrm{~min}$. The cells were then prepared as described in Hagan and Hyams (1988). Stained cells were observed as described in Gordon et al. (1996). Spores were germinated and prepared as described in Gordon et al. (1996). The following antisera were used (all at a dilution factor of 1 in 100) anti-Mts4, anti-20S, anti-HA (Babco) and anti-nuclear pore complex, mAB414 (Babco). Anti-Mts4 antiserum was also used after affinity purification at a dilution factor of 1 in 25 . Anti-rabbit and anti-mouse secondary antisera conjugated to either fluorescein isothiocyanate (FITC) (Sigma) used at a 1/100 dilution or Texas Red (Jackson) laboratories used at a 1/33 dilution were used to visualize the signal.

\section{Electron microscopic immunocytochemistry}

In preparation for immuno-localization, cells were harvested from a log phase culture by vacuum filtration, fast-frozen with liquid nitrogen in a Balzers HPM10 high pressure freezer and then freeze-substituted in $0.1 \%$ anhydrous glutaraldehyde dissolved in acetone at $-90^{\circ} \mathrm{C}$. After two days at this temperature, the specimens were warmed to room temperature and embedded in LR White, used according to the manufacturer's instructions. Serial sections were cut with a diamond knife, picked up on nickel slot grids coated with carbon-stabilized Formvar, and used immediately for immunolabeling.

The HA epitope was stained with a monoclonal antibody from Babco (HA.11) diluted to $10 \mu \mathrm{g} / \mathrm{ml}$ with a blocking buffer containing phosphatebuffered saline (PBS), $0.02 \%$ Tween-80, $0.8 \%$ BSA and $0.1 \%$ fish gelatin (Amersham, Arlington Heights, IL) to minimize non-specific binding. Sections mounted on grids were floated overnight on a $20 \mu \mathrm{l}$ drop of this solution at $4^{\circ} \mathrm{C}$ in a small chamber saturated with water vapour. The grids were then rinsed in buffered saline containing $0.1 \%$ Tween80 and stained for $2 \mathrm{~h}$ at room temperature with goat anti-mouse immunoglobulin labelled with $10 \mathrm{~nm}$ colloidal gold (British Biocell, Cardiff, UK), which had been centrifuged to remove gold aggregates and diluted 1:20 with blocking buffer, as above. The grids were fixed in $0.5 \%$ glutaraldehyde in PBS, stained with uranyl acetate and lead citrate, dried and examined in a Philips CM10 electron microscope operating at $80 \mathrm{kV}$.

\section{Visualization of GFP-tagged proteasomes}

For live-cell analysis a $p a d l^{+}-g f p h^{+}$strain (for mitosis) or a $p a d l^{+}$ $g f p h^{90}$ homothallic strain (for meiosis) was used with Pad1-GFP as the only source of the Pad1 protein. Mitotic cells were harvested from an exponentially growing culture in minimal medium and matings were set up by incubation for $12-18 \mathrm{~h}$ on malt extract medium. Cells were incubated at $25^{\circ} \mathrm{C}$ and embedded in minimal medium containing $0.5 \%$ low-melting point agarose on a microscope slide. The cells were observed using a $100 \times$ Neofluar 1.3 NA objective on a Zeiss Axioplan microscope (100 W Hg source) equipped with a Ludl filter wheel and a chroma 81000 filter set. The 81P490 filter was used for the excitation of GFP. For most image capture Digital Scientific SmartCapture running within the IPLab host programme was used to control a Photometrics Nu200 cooled CCD camera and filter wheel. Cells were exposed for $1 \mathrm{~s}$ every $30 \mathrm{~s}$ for a total of $20 \mathrm{~min}$. For deconvolution, a stack of images was collected using Bysis Viewpoint software in the $z$ axis at intervals of $0.5 \mu \mathrm{m}$. To remove out-of-focus haze, these images were deconvolved using the haze buster extension of IPLab spectrum (Scantalytics).

\section{Acknowledgements}

We thank Alison Pidoux for GFP-containing vectors and advice on microscopic analysis and Sandy Bruce, Norman Davidson and Douglas Stuart for photography. We also thank Gordon McGurk, Mary Penney, Susan Thomson and Nick Hastie for advice and encouragement. This work was supported by Medical Research Council funding to C.W., M.W., J.-P.J. and C.G., and by an NIH grant RR00592 to M.M. and J.R.M.

\section{References}

Akhayat,O., Grossi de Sa,F. and Infante,A.A. (1987) Sea urchin prosome: characterization and changes during development. Proc. Natl Acad. Sci. USA, 84, 1595-1599.

Amsterdam,A., Pitzer,F. and Baumeister,W. (1993) Changes in intracellular localization of proteasomes in immortalized ovarian granulosa cells during mitosis associated with a role in cell cycle control. Proc. Natl Acad. Sci. USA, 90, 99-103.

Beyette,J.R. and Mykles,D.L. (1992) Immunocytochemical localization of the multicatalytic proteinase (proteasome) in crustacean striated muscles. Muscle Nerve, 15, 1023-1035.

Biederer,T., Volkwein,C. and Sommer,T. (1996) Degradation of subunits of the Sec61p complex, an integral component of the ER membrane, by the ubiquitin-proteasome pathway. EMBO J., 15, 2069-2076.

Chen,P. and Hochstrasser,M. (1996) Autocatalytic subunit processing couples active site formation in the $20 \mathrm{~S}$ proteasome to completion of assembly. Cell, 86, 961-972.

Chikashige,Y., Ding,D.-Q., Funabiki,H., Haraguchi,T., Mashiko,S., Yanagida,M. and Hiraoka,Y. (1994) Telomere-led premeiotic chromosome movement in fission yeast. Science, 264, 270-273.

Ciechanover,A. (1994) The ubiquitin-proteasome proteolytic pathway. Cell, 79, 13-21.

Coux,O., Tanaka,K. and Goldberg,A.L. (1996) Structure and functions of the 20S and 26S proteasomes. Annu. Rev. Biochem., 65, 801-847.

DeMarini,D.J., PapaF.R., Swaminathan,S., Ursic,D., Rasmussen,T.P., Culbertson,M.R. and Hochstrasser,M. (1995) The yeast SEN3 gene encodes a regulatory subunit of the $26 \mathrm{~S}$ proteasome complex required for ubiquitin-dependent protein degradation in vivo. Mol. Cell. Biol., 15, 6311-6321.

Deveraux,Q., Ustrell,V., Pickart,C. and Rechsteiner,M. (1994) A 26S protease subunit that binds ubiquitin conjugates. J. Biol. Chem., 269, 7059-7061.

Dubiel,W., Ferrell,K. and Rechsteiner,M. (1995) Subunits of the regulatory complex of the 26S proteasome. Mol. Biol. Rep., 21, 27-34.

Feldherr,C.M., Kallenbach,E. and Schulz,N. (1984) Movement of a karyophilic protein through the nuclear pores of oocytes. J. Cell Biol., 99, 2216-2222.

Fujiwara,T., Watanabe,T.K., Tanaka,K., Slaughter,C.A. and DeMartino, G.N. (1996) cDNA cloning of p42, a shared subunit of two proteasome regulatory proteins, reveals a novel member of the AAA protein family. FEBS Lett., 387, 184-188. 
Gerace,L. (1992) Molecular trafficking across the nuclear pore complex. Curr. Opin. Cell Biol., 4, 637-645.

Ghislain,M., Udvardy,A. and Mann,C. (1993) S.cerevisiae 26S protease mutants arrest cell division in G2/metaphase. Nature, 366, 358-362.

Glickman,M.H., Rubin,D.M., Fried,V.A. and Finley,D. (1998) The regulatory particle of the Saccharomyces cerevisiae proteasome. Mol. Cell. Biol., 18, 3149-3162.

Gordon,C., McGurk,G., Dillon,P., Rosen,C. and Hastie,N.D. (1993) Defective mitosis due to a mutation in the gene for a fission yeast 26S protease subunit. Nature, 366, 355-357.

Gordon,C., McGurk,G., Wallace,M. and Hastie,N.D. (1996) A conditional lethal mutant in the fission yeast $26 \mathrm{~S}$ protease subunit $m t s 3^{+}$is defective in metaphase to anaphase transition. J. Biol. Chem., 271, 5704-5711.

Groll,M., Ditzel,L., Lowe,J., Stock,D., Bochtler,M., Bartunik,H.D. and Huber,R. (1997) Structure of $20 \mathrm{~S}$ proteasome from yeast at $2.4 \AA$ resolution. Nature, 386, 463-471.

Grossi de Sa,M.-F., Martins de Sa,C., Harper,F., Olink-Coux,M., Huesca,M. and Scherrer,K. (1988) The association of prosomes with some of the intermediate filament networks of the animal cell. J. Cell Biol., 107, 1517-1530.

Hagan,I.M. and Hyams,J.S. (1988) The use of cell division cycle mutants to investigate the control of microtubule distribution in the fission yeast Schizosaccharomyces pombe. J. Cell Sci., 89, 343-357.

Haracska,L. and Udvardy,A. (1995) Cloning and sequencing of a nonATPase subunit of the regulatory complex of the Drosophila 26S protease. Eur. J. Biochem., 231, 720-725.

Heinemeyer,W., Fischer,M., Krimmer,T., Stachon,U. and Wolf,D.H. (1997) The active sites of the eukaryotic 20S proteasome and their involvement in subunit precursor processing. J. Biol. Chem., 272, 25200-25209.

Hershko,A. (1988) Ubiquitin-mediated protein degradation. J. Biol. Chem., 263, 15237-15240.

Hershko,A. and Ciechanover,A. (1992) The ubiquitin system for protein degradation. Annu. Rev. Biochem., 61, 761-807.

Hiller,M.M., Finger,A., Schweiger,M. and Wolf,D.H. (1996) ER degradation of a misfolded luminal protein by the cytosolic ubiquitinproteasome pathway. Science, 273, 1725-1728.

Hochstrasser,M. (1995) Ubiquitin, proteasomes and the regulation of intracellular protein degradation. Curr. Opin. Cell Biol., 7, 215-223.

Jentsch,S. and Schlenker,S. (1995) Selective protein degradation. A journey's end within the proteasome. Cell, 82, 881-884.

Kawahara,H. and Yokosawa,H. (1992) Cell-cycle dependent change of proteasome distribution during embryonic development of the ascidian Halocynthia roretzi. Dev. Biol., 151, 27-33.

King,R.W., Deshaies,R.J., Peters,J.-M. and Kirschner,M.W. (1996) How proteolysis drives the cell cycle. Science, 274, 1652-1659.

Klein,U., Gernold,M. and Kloetzel,P.-M. (1990). Cell-specific accumulation of Drosophila proteasomes (MCP) during early development. J. Cell Biol., 111, 2275-2282.

Kloetzel,P.-M., Falkenburg,P-E., Hössl,P. and Glötzer,K.H. (1987) The 19S ring-type particles of Drosophila. Exp. Cell Res., 170, 204-213.

Knuehl,C., Seelig,A., Brecht,B., Henklein,P. and Kloetzel,P.-M. (1996) Functional analysis of eukaryotic $20 \mathrm{~S}$ proteasome nuclear localization signal. Exp. Cell Res., 225, 67-74.

Kominami,K. et al. (1995) Nin1p, a regulatory subunit of the 26S protease is necessary for activation of Cdc28p kinase of Saccharomyces cerevisiae. ЕMBO J., 14, 3105-3115.

Kominami,K. et al. (1997) Yeast counterparts of subunits S5a and p58 (S3) of the human 26S proteasome are encoded by two multicopy suppressors of nin1-1. Mol. Biol. Cell, 8, 171-187.

Lam,Y.A., Xu,W., DeMartino,G.N. and Cohen,R.E. (1997) Editing of ubiquitin conjugates by an isopeptidase in the $26 \mathrm{~S}$ proteasome. Nature, 385, 737-740.

Lowe,J., Stock,D., Jap,B., Zwickl,P., Baumeister,W. and Huber,R. (1995) Crystal structure of the $20 \mathrm{~S}$ proteasome from the Archaeon T.acidophilum at $3.4 \AA$ resolution. Science, 268, 533-539.

Lupas,A., Koster,A.J. and Baumeister,W. (1993) Structural features of 26S and 20S proteasomes. Enzyme Protein, 47, 252-273.

Maundrell,K. (1993) Thiamine-repressible expression vectors pREP and pRIP for fission yeast. Gene, 123, 127-130.

McDonald,H.B. and Byers,B. (1997) A proteasome cap subunit required for spindle pole body duplication in yeast. J. Cell Biol., 137, 539-553.

Moreno,S., Klar,A. and Nurse,P. (1991) Molecular genetic analysis of the fission yeast Schizosaccharomyces pombe. Methods Enzymol., 194, 795-823.
Nederlof,P.M., Wang,H.R. and Baumeister,W. (1995) Nuclear localization signals of human and Thermoplasma proteasomal alpha subunits are functional in vitro. Proc. Natl Acad. Sci. USA, 92, 12060-12064.

Ohno,M., Fornernod,M. and Mattaj,I.W. (1998) Nucleocytoplasmic transport: the last 200 nanometers. Cell, 92, 327-336.

Pal,J.K., Gounon,P., Grossi de Sa,M.F. and Scherrer,K. (1988) Presence and distribution of specific prosome antigens change as a function of embryonic development and tissue-type differentiation in Pleurodeles waltl. J. Cell Sci., 90, 555-567.

Palmer,A. Rivett,A.J., Thomson,S., Hendil,K.B., Butchers,G.W., Fuertes,G. and Knecht,E. (1996) Subpopulations of the 26S proteasomes in rat liver nuclei, microsomes and cytosol. Biochem. J., 316, 401-407.

Pemberton,L.F., Blobel,G. and Rosenblum,J.S. (1998) Transport routes through the nuclear pore. Curr. Opin. Cell Biol., 10, 392-399.

Penney,M. et al. (1998) The padl ${ }^{+}$gene encodes a subunit of the 26S proteasome in fission yeast. J. Biol. Chem., 273, 23938-23945.

Peters,J.-M. (1994) Proteasomes-protein degradation machines of the cell. Trends Biochem. Sci., 19, 377-382.

Peters,J.-M., Franke,W.W. and Kleinschmidt,J.A. (1994) Distinct 19S and $20 \mathrm{~S}$ subcomplexes of the $26 \mathrm{~S}$ proteasome and their distribution in the nucleus and the cytoplasm. J. Biol. Chem., 269, 7709-7718.

Plemper,R.K., Bohmler,S., Bordallo,J., Sommer,T. and Wolf,D.H. (1997) Mutant analysis links the translocon and Bip to retrogade transport for ER degradation. Nature, 388, 891-895.

Prentice,H. (1991) High efficiency transformation of Schizosaccharomyces pombe. Nucleic Acids Res., 20, 621.

Rechsteiner,M., Hoffman,L. and Dubiel,W. (1993) The multicatalytic and 26S proteases. J. Biol. Chem., 268, 6065-6068.

Reits,E.A.J., Benham,A.M., Plougastel,B., Neefjes,J. and Trowsdale,J. $(1997)$ Dynamics of proteasome distribution in living cells. EMBO J., 16, 6087-6094.

Rivett,A.J., Palmer,A. and Knecht,E. (1992) Electron microscopic localization of the multicatalytic proteinase complex in rat liver and in cultured cells. J. Histochem. Cytochem., 40, 1165-1172.

Rout,M.P. and Blobel,G. (1993) Isolation of the yeast nuclear pore complex. J. Cell Biol., 123, 771-783.

Schmidtke,G., Kraft,R., Kostka,S., Henklein,P., Frommel,C., Lowe,J., Huber,R., Kloetzel,P.M. and Schmidt,M. (1996) Analysis of mammalian 20S proteasome biogenesis: the maturation of $\beta$-subunits is an ordered two-step mechanism involving autocatalysis. EMBO J., 15, 6887-6898.

Seeger,M., Gordon,C., Ferrell,K. and Dubiel,W. (1996) Characteristics of $26 \mathrm{~S}$ proteases from fission yeast mutants which arrest in mitosis. J. Mol. Biol., 263, 423-431.

Seemueller,E., Lupas,A. and Baumeister,W. (1996) Autocatalytic processing of the 20S proteasome. Nature, 382, 468-471.

Shimanuki,M., Saka,Y., Yanagida,M. and Toda,T. (1995) A novel essential fission yeast gene $\mathrm{padl}^{+}$positively regulates $\mathrm{papl}^{+}$. J. Cell Sci., 108, 569-579.

Spataro,V., Toda,T., Craig,R., Seeger,M., Dubiel,W., Harris,A.L. and Norbury,C. (1997) Resistance to diverse drugs and UV light conferred by overexpression of a novel $26 \mathrm{~S}$ proteasome subunit. J. Biol. Chem., 272, 30470-30475.

Stauber,W.T., Fritz,V.K., Maltin,C.A. and Dahlmann,B. (1987) Localization of multicatalytic, high-molecular mass proteinase in the nuclei of muscle cells. Histochem. J., 19, 594-597.

Tanahashi,N., Tsurumi,C., Tamura,T. and Tanaka,K. (1993) Molecular structures of 20S and 26S proteasomes. Enzyme Protein, 47, 241-251.

Tanaka,K. and Tsurumi,C. (1997) The 26S proteasome: subunits and functions. Mol. Biol. Rep., 24, 3-11.

Tanaka,K., Yoshimura,T., Tamura,T., Fujiwara,A., Kumatori,A. and Ichihara,A.A. (1990) Possible mechanisms of nuclear translocation of proteasomes. FEBS Lett., 271, 41-46.

Toda,T., Yamamoto,M. and Yanagida,M. (1981) Sequential alterations in the nuclear chromatin region during mitosis of the fission yeast Schizosaccharomyces pombe-video fluorescence microscopy of synchronously growing wild-type and cold sensitive $c d c$ mutants by using a DNA-binding fluorescent probe. J. Cell Sci., 52, 271-287.

van Nocker,S., Deveraux,Q., Rechsteiner,M. and Vierstra,R.D. (1996) Arabidopsis MBP1 gene encodes a conserved ubiquitin recognition component of the 26S proteasome. Proc. Natl Acad. Sci. USA, 93, 856-860.

Weiss,K. (1998) Importins and exportins: how to get in and out of the nucleus. Trends Biochem. Sci., 23, 185-189. 


\section{C.R.M.Wilkinson et al.}

Werner,E.D., Brodsky,J.L. and McCracken,A.A. (1996) Proteasomedependent endoplasmic reticulum-associated protein degradation: an unconventional route to a familiar fate. Proc. Natl Acad. Sci. USA, 93, 13797-13801.

Wilkinson,C.R.M., Wallace,M., Seeger,M., Dubiel,W. and Gordon,C. (1997) Mts4, a non-ATPase subunit of the $26 \mathrm{~S}$ protease in fission yeast is essential for mitosis and interacts directly with the ATPase subunit Mts2. J. Biol. Chem., 272, 25768-25777.

Yang,Y., Fruh,K., Ahn,K. and Peterson,P.A. (1995) In vivo assembly of the proteasomal complexes, implications for antigen processing. J. Biol. Chem., 270, 27687-27694.

Yoshimura,T. et al. (1993) Molecular characterization of the '26S' proteasome complex from rat liver. J. Struct. Biol., 111, 200-211.

Received August 10, 1998; accepted September 17, 1998

\section{Note added in proof}

The pad1-GFP movies showing the localisation of the 26S proteasome in fission yeast during mitosis and meiosis can be accessed at the following website: http://www.hgu.mrc.ac.uk/Research/Devgen/ Proteolysis/colin.htm 